\title{
Restoration of the glycogen-forming function of hepatocytes in rats with liver cirrhosis is facilitated by a high-carbohydrate diet
}

\author{
Margarita V. Kudryavtseva*, Natalia N. Besborodkina and Boris N. Kudryavtsev \\ Institute of Cytology, Russian Academy of Sciences, St Petersburg, Russia
}

(Received 26 March 1998 - Revised 18 December 1998 - Accepted 6 January 1999)

\begin{abstract}
Using cytofluorimetric and biochemical methods, the content of glycogen and its labile and stable fractions, as well as activities of glucose-6-phosphatase (EC 3.1.3.9), glycogen phosphorylase (EC 2.4.1.1) and glycogen synthase (EC 2.4.1.11) were determined in the rat liver for 6 months after chronic poisoning of the animals with $\mathrm{CCl}_{4}$ and then at 1,3 , and 6 months after the end of the poisoning. One group of rats was given a standard diet, the other, a high-carbohydrate diet. The 6-month long chronic intoxication with $\mathrm{CCl}_{4}$ was shown to produce development of typical liver cirrhosis characterized by a $2 \cdot 8$-fold increase in the total glycogen content in hepatocytes as compared with normal cells, by a fall in the glycogen labile fraction (from 85 to $53 \%$ of the total glycogen) as well as by decreases in the activities of glycogen phosphorylase and glucose-6phosphatase by 25 and $82 \%$ respectively. The structural rehabilitation occurred faster and more completely at the cellular level than at the tissue level. Functional variables of the cirrhotic liver tissue also recovered, after cessation of poisoning, faster and more completely than the liver structure at the tissue level: glycogen levels in hepatocytes fell dramatically, the labile:stable glycogen fraction ratio recovered completely, and the activity of glycogen phosphorylase rose to the level characteristic of the normal liver. Use of the high-carbohydrate diet promoted a somewhat faster and more complete recovery of hepatic structure and function.
\end{abstract}

\section{Liver cirrhosis: Glycogen: High-carbohydrate diet}

Liver cirrhosis is a most common and severe human pathology. It causes different disturbances in various liver functions and specifically the glycogen-forming function. To achieve rehabilitation of numerous impaired functions of the cirrhotic liver is a task of great practical importance. There are encouraging data in the literature about the reversibility of cirrhotic changes in the hepatic parenchyma (Solopaev, 1985; Sarkisov, 1987). One of the approaches in therapy of liver cirrhosis is to give a special diet with a high carbohydrate content. Such a diet has been shown to increase resistance of hepatocytes to the effects of damaging factors (Jennische, 1983; Frederiks et al. 1985) and to promote the functional efficiency of the liver (Hinson et al. 1983; Kabadi et al. 1985), whereas fasting, in contrast, is known to enhance impairment of this organ (Diaz-Gomes et al. 1975; Pushpendran et al. 1977). Meanwhile, liver cirrhosis is accompanied by a progressive starvation (Anthonius et al. 1991) which is probably due to impairment of glucose utilization and activation of energy metabolism (Proietto et al. 1980). In this connection, the use of glucose is highly recommended in the treatment of liver cirrhosis in clinical practice (Kabadi et al. 1985). The liver plays a major role in the regulation of blood glucose levels because it is capable of synthesizing and degrading glycogen in its parenchymal cells, i.e. owing to its glycogen-forming functions.

The aim of the present work was to study the recovery of glycogen-forming function of rat hepatocytes following chemically-induced damage. We determined levels of glycogen and its fractions in hepatocytes, and the activities of some enzymes of glycogen metabolism, in the cirrhotic rat liver at various time intervals after termination of $\mathrm{CCl}_{4}$ poisoning and addition to the food of a glucose-sucrose mixture.

\section{Materials and methods \\ Animals, biopsies, and diets}

The study was performed on adult white breedless male rats weighing initially $120-150 \mathrm{~g}$. The liver cirrhosis in the animals was produced by inhalation of the hepatotropic poison $\mathrm{CCl}_{4}$. The animals were poisoned for 6 months in a special closed chamber of 40 litres volume three times weekly, 
for $15 \mathrm{~min}$ (the concentration of $\mathrm{CCl}_{4}$ was $0.05 \mathrm{~g} / \mathrm{l}$; Kudryavtseva et al. 1994). The degree of cirrhosis development was evaluated by histological examination of haematoxylineosin- and van Gieson-stained liver sections.

Under light diethyl ether anaesthesia, always at 10.0012.00 hours, punctate needle biopsies of the liver were obtained from each animal several times: before poisoning, at the time of cirrhosis development (6 months after the start of the poisoning with $\mathrm{CCl}_{4}$ ) then 1,3 , and 6 months after the start of recovery (on termination of the 6-month-long poisoning). On termination of the poisoning, one group of rats was kept throughout the recovery period on a standard diet (SD group); a second group received, in addition to the standard diet, a high-carbohydrate mixture: $50 \mathrm{~g} / \mathrm{l}$ glucose$150 \mathrm{~g} / \mathrm{l}$ sucrose solutions $(1: 1, \mathrm{v} / \mathrm{v})$ (HC group). As a control, a third group of rats of the same age was used, with no poisoning. Each group comprised five rats.

The liver tissue material from each animal was used, (1) for sections to be examined histologically, (2) for smears of isolated hepatocytes on object glasses by our own method (Kudryavtseva et al. 1983) for quantitative cytochemistry, (3) for microchemical determinations of activities of some enzymes of glycogen metabolism.

\section{Cytofluorimetry of total glycogen and its fractions}

The contents of total glycogen and its labile fraction and stable fraction in hepatocytes were measured cytofluorimetrically in the smears stained with a fluorescent periodic acid-Schiff (PAS)-reaction. The smears of isolated hepatocytes were obtained from the supravital punctate biopsy of the liver, using two phosphate buffers: (1) $\mathrm{pH} 8.0$ and (2) $\mathrm{pH}$ 7.4 into which the punctate pieces were placed consecutively for 10 and $15 \mathrm{~min}$ respectively. We developed a method of detecting glycogen in hepatocytes, using the fluorescent dye auramine OO-SO ${ }_{2}$ (Schiff-type reagent), as a modification of the routine PAS-reaction. The fluorescent PAS-reaction was performed as follows: the preparations, smears of isolated hepatocytes, were oxidized for $90 \mathrm{~min}$ in $\mathrm{KIO}_{4}$ solution $(8 \mathrm{~g} / \mathrm{l}) 0 \cdot 01 \mathrm{M}-\mathrm{HNO}_{3}$ at $\mathrm{pH} 2 \cdot 2$. After rinsing in tap and distilled waters, the preparations were placed into a $\mathrm{SO}_{2}$-saturated $(0 \cdot 2 \mathrm{ml}$ thionyl chloride $)$ $4.5 \mathrm{~g} / \mathrm{l}$ auramine solution for $40 \mathrm{~min}$ (for determination of the labile glycogen fraction) or for $90 \mathrm{~min}$ (for total glycogen); the stable glycogen fraction was calculated as the difference between these two glycogen fractions. The preparations were dehydrated using the standard procedure: $\mathrm{SO}_{2}$-waters, tap water, alcohols of increasing concentrations. Specificity of the fluorescent staining for glycogen was confirmed by a control treatment of the preparations with $\alpha$-amylase (EC 3.2.1.1) (Sigma, St Louis, MO, USA) by the standard procedure (Rosa \& Johnson, 1967): $60 \mathrm{~min}$, at $37^{\circ}$, with a $10 \mathrm{~g} / \mathrm{l}$ solution of the enzyme.

Several controls confirmed a substantial specificity of this reagent. Using auramine $\mathrm{OO}-\mathrm{SO}_{2}$, the microfluorimetric method was shown to be suitable for the quantitative determination of glycogen in hepatocytes. The data obtained agreed well with the results of glycogen measurements by routine absorptional cytophotometry, using the standard Schiff reagent. Effects of the duration of periodate oxidation and of staining with auramine- $\mathrm{SO}_{2}$ on the intensity of the fluorescent PAS-reaction were studied. As a result, the optimal time for oxidation and staining was established. Thus, the fluorescent PAS-reaction was shown to be highly specific and to depend on glycogen alone, and the possibility was confirmed of revealing and measuring quantitatively the amounts of total glycogen and its labile and stable fractions in individual cells (Kudryavtseva $e t a l$. 1974).

The measurements were performed in isolated hepatocytes, using a cytofluorimeter designed at our laboratory (Rozanov \& Kudryavtsev, 1967; Kudryavtseva et al. 1972). In each preparation, 500-600 cells were measured.

\section{Microchemical determination of enzyme activities}

The enzyme activities in the rat liver biopsies were determined using standard methods specially modified for small amounts of the material $(10-30 \mathrm{mg})$. The biopsy pieces were homogenized at $2-4^{\circ}$ in the diluted buffer $(1: 6, \mathrm{v} / \mathrm{v})$ that contained (mmol/l): 50 Tris- $\mathrm{HCl}(\mathrm{pH} \mathrm{7.4),} 250$ sucrose, $60 \mathrm{NaF}, 5 \mathrm{EDTA}$. The homogenate was centrifuged for $10 \mathrm{~min}$ at $12000 \mathrm{~g}$, and the supernatant fraction was used for the spectrophotometric determination of the enzyme activities. Activities of glucose-6-phosphatase (EC 3.1.3.9) and glycogen phosphorylase (EC 2.4.1.1) were determined by the methods of Swanson (1950) and Hers (1964) respectively, by measuring changes in the content of inorganic phosphate formed during the course of the reaction (Nordlie, 1979). The activity of glycogen synthase (EC 2.4.1.11) was measured in a coupled system of pyruvate kinase ( $E C$ 2.7.1.40) and lactate dehydrogenase (EC 1.1.1.2) (Barber et al. 1967) using a Specoll 11 spectrophotometer (Carl Zeiss Jena GmbH, Jena, Germany). In all cases, the enzyme activity depended on the protein content in the sample and was proportional to the incubation time. The protein content was determined by the method of Lowry et al. (1951). The protein content calculations were made using a calibration curve. Bovine serum albumin was used as the standard.

\section{Microscopy of liver sections}

Morphological examination and photography of the liver sections stained with haematoxylin-eosin and van Gieson stains were performed under an Amplival microscope (Carl Zeiss Jena $\mathrm{GmbH}$ ) with a $40 \times$ objective lens and $4 \times$ eyepiece. The examination and photography of hepatocytes stained with the fluorescent PAS-reaction for glycogen were done using a LUMAM I-1 luminescent microscope (LOMO, St Petersburg, Russia) with objective lenses $90 \times$ and $20 \times$.

All the data obtained were treated statistically using Student's $t$ test, and when appropriate, the $\chi^{2}$ criterion, using Statographics 5.0 (Manugistics Inc., Rockville, MD, USA) and SigmaPlot for Windows 1.0 (Jandel Corporation, Jandel Scientific GmbH, Erkrath, Germany).

\section{Results \\ Structure of the liver parenchyma}

Morphological analysis of the liver showed (Fig. 1(a)) that in control animals the hepatic parenchyma was characterized by a distinct radial distribution of hepatocyte cords around 

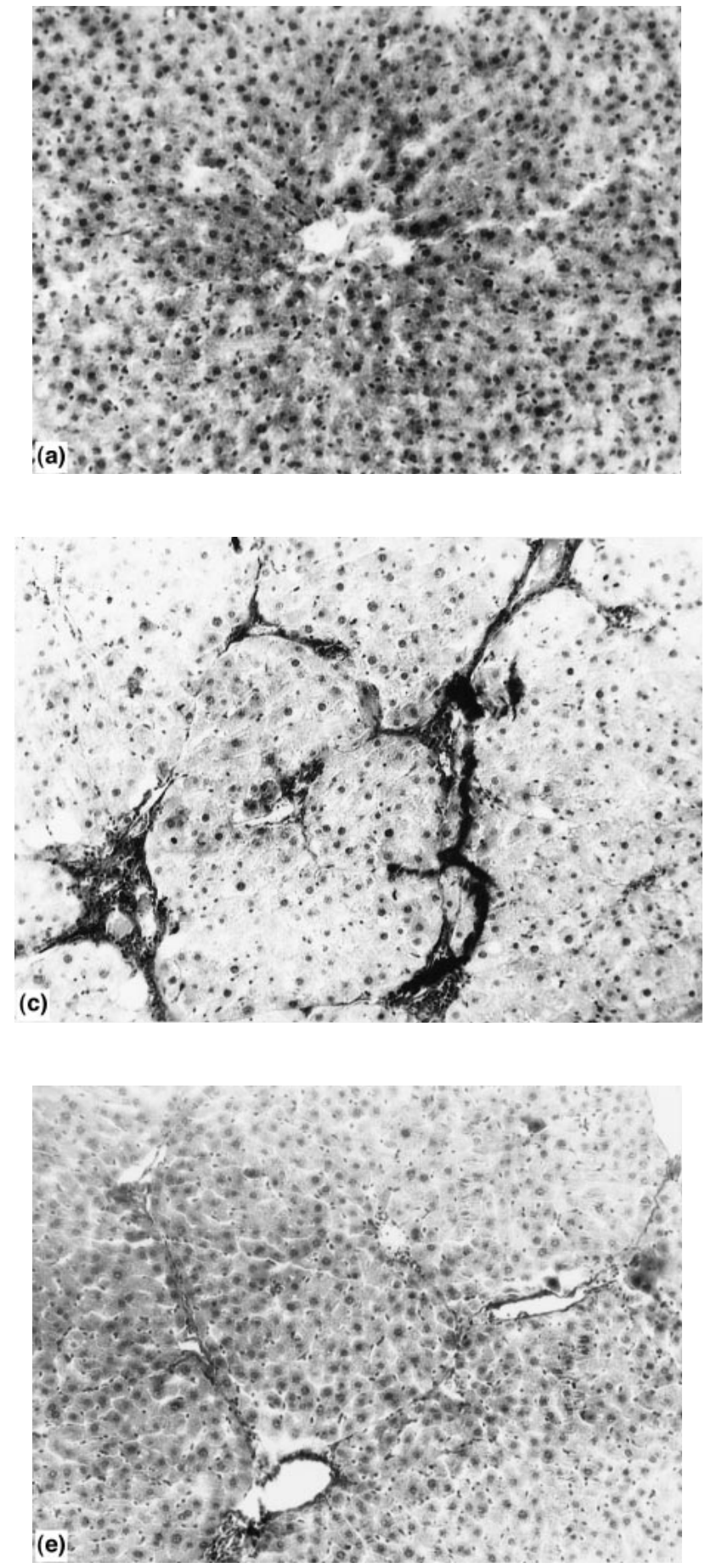
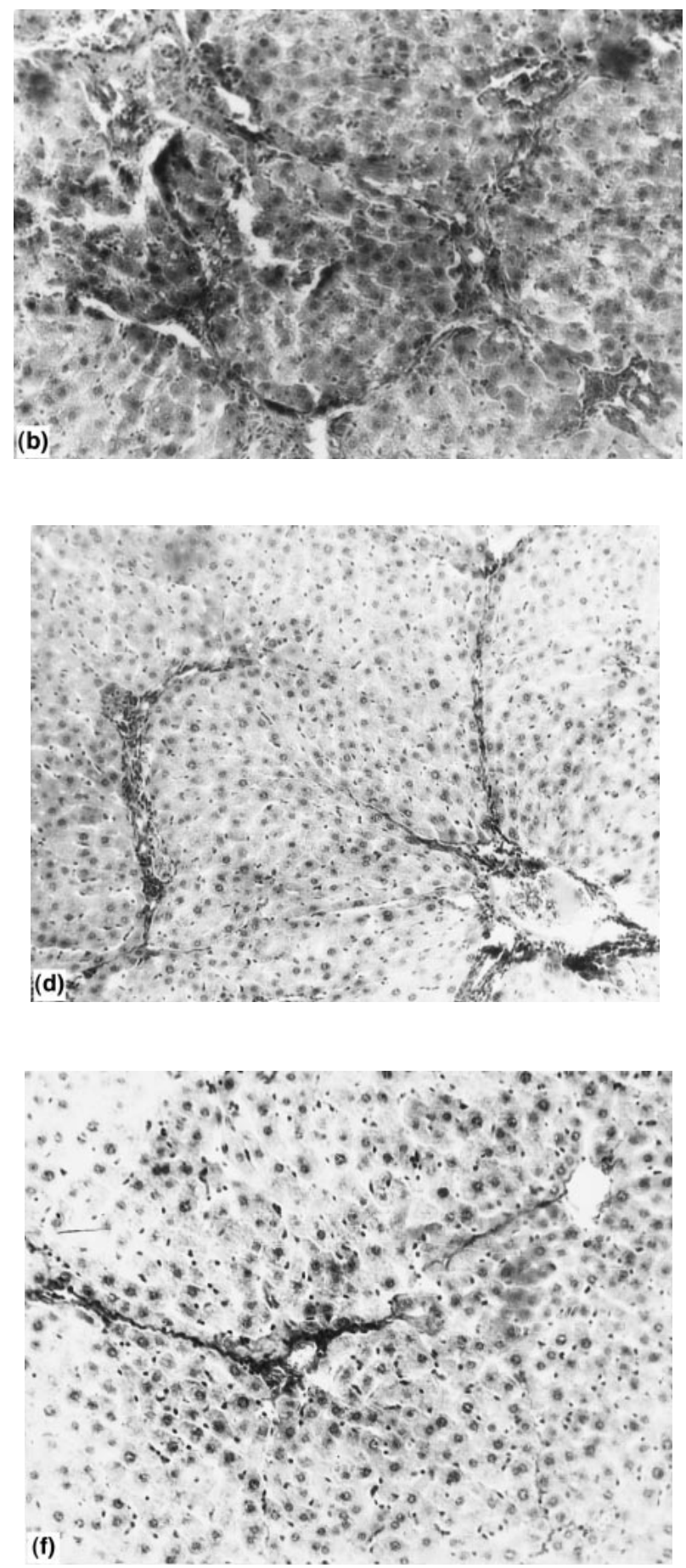

Fig. 1. Sections of liver from (a) a normal rat; $(b, c)$ rats with liver cirrhosis induced by chronic poisoning with carbon tetrachloride; and (d, e, f) rats with induced liver cirrhosis after rehabilitation for 1,3 and 6 months respectively on a high-carbohydrate diet. Sections were stained with haematoxylin-eosin (a, b, d, e, f) or van Gieson (c) stains. Objective $40 \times$, eye piece $4 \times$.

central veins, by thin walls of the portal tract vessels, and by other features typical of the normal liver. In cirrhosis, the lobular liver structure disappeared (Fig. 1(b, c)), the connective tissue bands grew into the liver parenchyma and divided it into the pseudolobules whose centres often failed to contain the central vein lumen. In the parenchyma, large leucocyte infiltrates and numerous Kupffer cells appeared, which is characteristic of this pathology. In 3-6 months (depending on individual peculiarities of the animals) after termination of the $\mathrm{CCl}_{4}$ poisoning, the connective tissue bands that disturbed the normal lobular structure became thinner (Fig. 1(d, e, f)). The leucocyte infiltrates disappeared, 

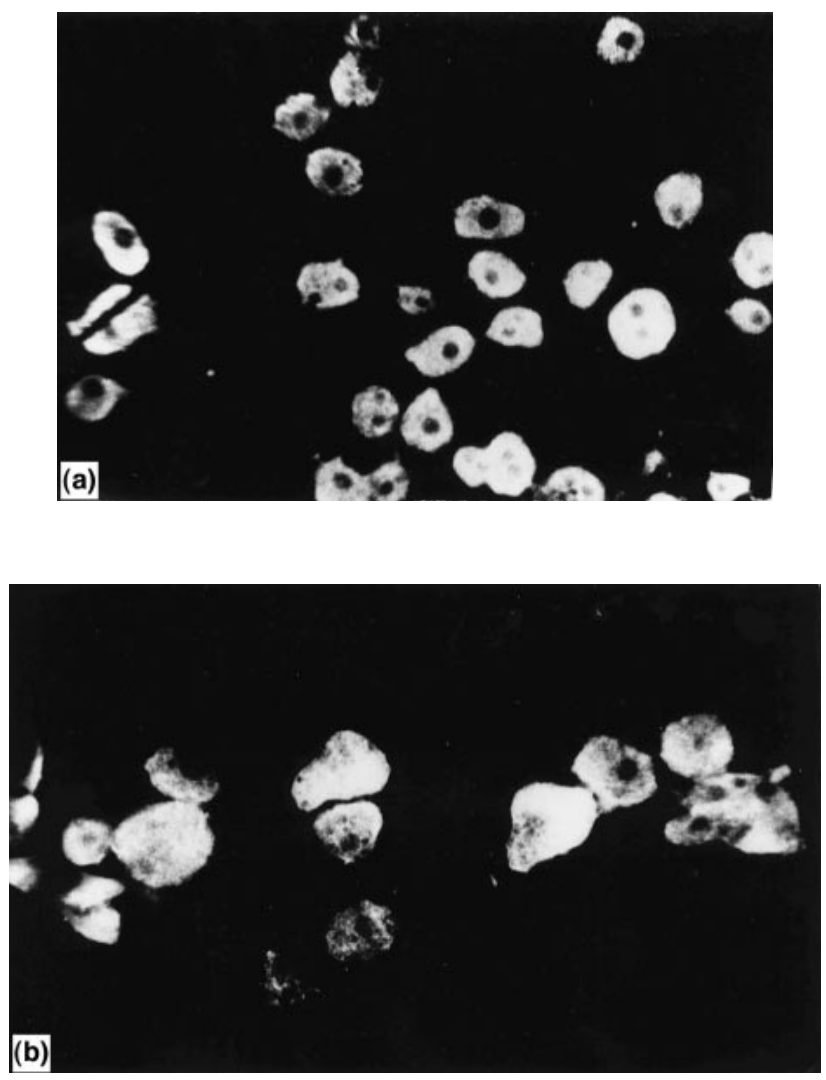

Fig. 2. Hepatocytes from (a) a normal rat and (b) a rat with liver cirrhosis induced by chronic poisoning with carbon tetrachloride, stained by the fluorescent peroidic acid-Schiff reaction. Objective $20 \times$, eye piece $3 \times$.

and the number of Kupffer cells decreased, which indicated a tendency for recovery of the normal liver structure.

Examination of hepatocytes by luminescent microscopy, on performance of the fluorescent PAS-reaction, showed that whereas normal hepatocytes were characterized by a fine structure and distinct contours of the nucleus and cytoplasm (Figs. 2(a), 3(a)), in cirrhosis, a pronounced polymorphism of the cells was revealed with respect to both their size and shape and to their structure (Figs. 2(b), $3(b))$. In the cirrhotic liver, apart from the hepatocytes rather close morphologically to normal cells, there were quite a few cells with a blurred clumped cytoplasm and indistinct contours of the nucleus and cytoplasm. On termination of the poisoning, in rats of the $\mathrm{HC}$ group, the structure of hepatocytes had improved by as early as 1 month and had become close to normal in 6 months (Fig. 3(c)). In animals of the SD group, these changes in the hepatocyte structure tended to be similar, but they were less pronounced. Thus, on termination of the hepatotoxic effect, changes in the liver structure at the cytological level were characterized by a more substantial tendency for normalization than changes at the tissue level.

\section{Glycogen content}

In control rats that had not undergone poisoning or surgery, the amounts of total glycogen and its labile and stable fractions per cell remained practically constant throughout the entire duration of the experiment.

As seen from Table 1, the total glycogen content in hepatocytes from cirrhotic liver was $2 \cdot 8$-fold greater than in normal hepatocytes. With regard to the glycogen fraction composition, the liver cirrhosis was characterized by a significant reduction (down to $53 \%$ ) of the labile fraction and a corresponding rise in the stable fraction in hepatocytes (Table 1).

After the end of the hepatotropic poisoning period, the total glycogen content in hepatocytes was decreasing, the reduction being in 1 month approximately the same in the SD and HC groups of rats: by 1.92 and 1.86 times respectively. However, the subsequent changes in cell glycogen level were somewhat different in these two groups of animals. The glycogen concentration continued to decrease slowly in the SD group, while it remained stable in the HC group (Table 1, Fig. 4(a, b)). As a result, 6 months after the termination of the $\mathrm{CCl}_{4}$ poisoning, the total glycogen content in hepatocytes of the SD group reached the level characteristic of the normal liver, whereas in rats of the HC group it exceeded the normal level by about $35 \%$. At all

Table 1. Content of total glycogen (TG), its labile fraction (LF) and its stable fraction (SF) (arbitrary units) in the livers of rats before poisoning, during liver cirrhosis caused by 6 months treatment with carbon tetrachloride, and at various time intervals during rehabilitation on a standard diet (SD) or a high-carbohydrate diet (HC)‡

(Values are means with their standard errors for five rats)

\begin{tabular}{|c|c|c|c|c|c|c|c|c|c|c|c|}
\hline \multirow{2}{*}{$\begin{array}{l}\text { Form of } \\
\text { glycogen }\end{array}$} & & & & & & \multicolumn{6}{|c|}{ Length of rehabilitation (months) } \\
\hline & Mean & SE & Mean & SE & $\begin{array}{l}\text { Rehabilitation } \\
\text { strategy }\end{array}$ & Mean & SE & Mean & SE & Mean & SE \\
\hline \multirow[t]{2}{*}{$\mathrm{TG}$} & 37.6 & $1 \cdot 1$ & 82.1††† & 1.7 & SD & 42.7††† & 1.2 & 33.7††† & $1 \cdot 2$ & 32.4††† & $1 \cdot 3$ \\
\hline & $36 \cdot 8$ & 1.0 & $82 \cdot 1+\dagger \dagger$ & 1.7 & $\mathrm{HC}$ & $44.0^{*}+t \dagger$ & 0.8 & $45 \cdot 0^{* *}+\dagger \dagger$ & 0.6 & $42 \cdot 0^{\star \star}+\dagger$ & 0.5 \\
\hline LF & $32 \cdot 7$ & $1 \cdot 1$ & $53 \cdot 2+\dagger \dagger$ & 1.4 & SD & $32.9 \dagger$ & 1.1 & $27 \cdot 1+\dagger \dagger$ & 1.0 & $24 \cdot 7+\dagger \dagger$ & 0.3 \\
\hline
\end{tabular}

Mean values were significantly different from those for the SD group: ${ }^{\star} P<0.05,{ }^{\star *} P<0.01,{ }^{\star \star \star} P<0.001$.

Mean values were significantly different from the corresponding values before poisoning: $\uparrow P<0.05, \dagger \dagger P<0.01, \dagger \dagger \dagger P<0.001$.

$\ddagger$ For details of procedures, see pp. 473-474. 

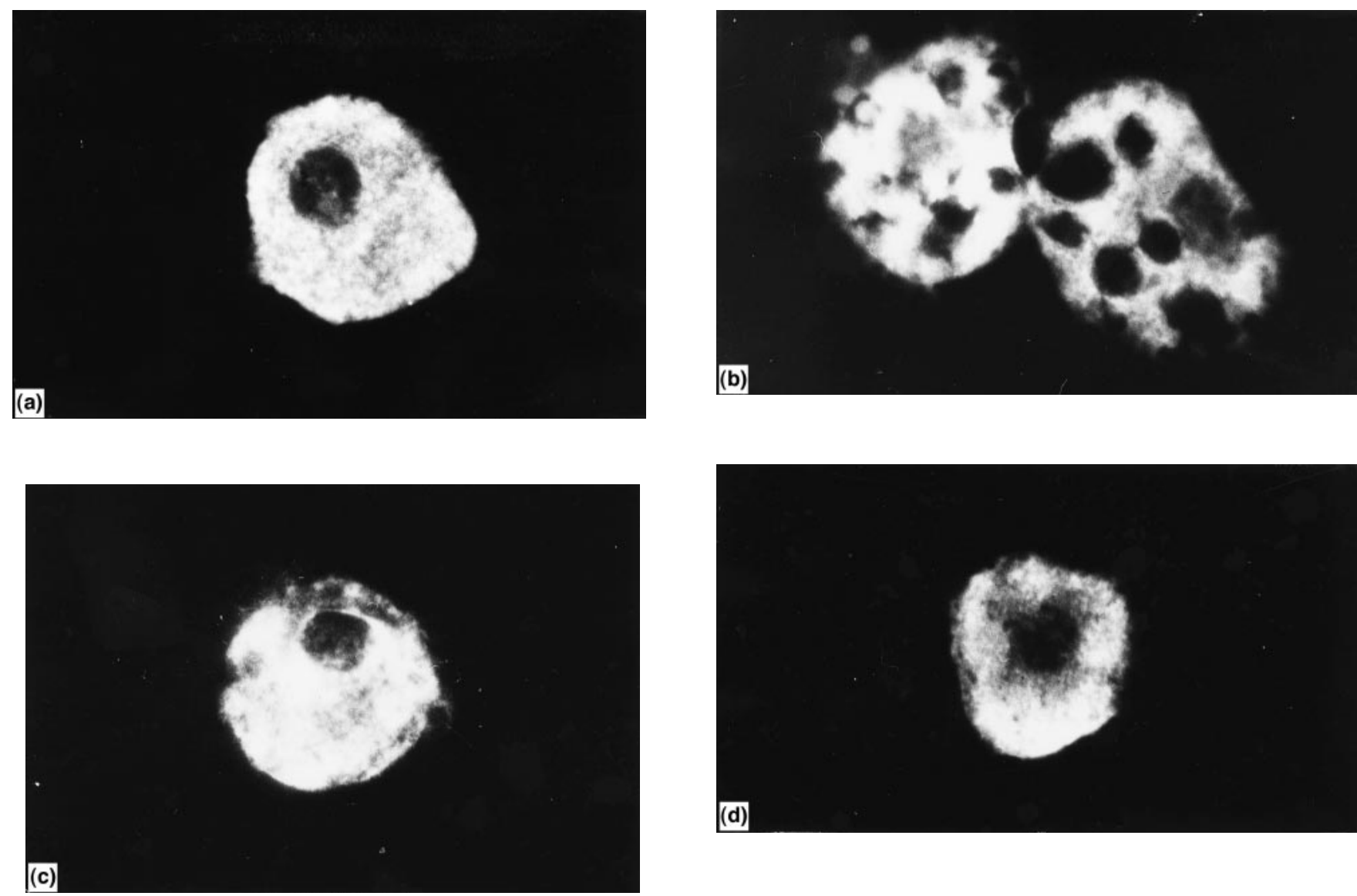

Fig. 3. Hepatocytes from (a) a normal rat; (b) a rat with liver cirrhosis induced by chronic poisoning with carbon tetrachloride; and (c, d) rats with induced liver cirrhosis after rehabilitation for 1 and 6 months respectively on a high-carbohydrate diet. Hepatocytes were stained by the fluorescent periodic acid-Schiff reaction. Objective $90 \times$, eye piece $3 \times$.

stages of the experiment, differences in the hepatic glycogen content between individual animals were less than $20 \%$.

Unlike the total glycogen content the fractional composition returned to normal, after the termination of the $\mathrm{CCl}_{4}$ poisoning, much faster in the $\mathrm{HC}$ group than in the SD group (Table 1). The percentage labile fraction in hepatocytes of the HC group reached normal values as early as 1 month after the end of poisoning, whereas in hepatocytes of the SD group it remained somewhat lower than normal even after 6 months of rehabilitation (Table 1).

Table 2. Activities of glucose-6-phosphatase (G6P), glycogen phosphorylase (GP) and glycogen synthase (GS) (nmol/min per mg protein) in the livers of rats before poisoning, during liver cirrhosis caused by 6 months treatment with carbon tetrachloride, and at various time intervals during rehabilitation on a standard diet (SD) or a high-carbohydrate diet $(\mathrm{HC}) \ddagger$

(Values are means with their standard errors for five rats)

\begin{tabular}{|c|c|c|c|c|c|c|c|c|c|c|c|}
\hline \multirow[b]{3}{*}{ Enzyme } & & & & & \multirow{3}{*}{$\begin{array}{l}\text { Rehabilitation } \\
\text { strategy }\end{array}$} & \multicolumn{6}{|c|}{ Length of rehabilitation (months) } \\
\hline & \multicolumn{2}{|c|}{ Before poisoning } & \multicolumn{2}{|c|}{ Liver cirrhosis } & & \multicolumn{2}{|l|}{1} & \multicolumn{2}{|l|}{3} & \multicolumn{2}{|l|}{6} \\
\hline & Mean & SE & Mean & SE & & Mean & SE & Mean & SE & Mean & SE \\
\hline \multirow[t]{2}{*}{ G6P } & $79 \cdot 2$ & $7 \cdot 0$ & 18.2††† & $5 \cdot 1$ & SD & $65 \cdot 4 \uparrow † \dagger$ & $5 \cdot 5$ & 61.2††† & $4 \cdot 8$ & $44.9+† \dagger$ & $2 \cdot 8$ \\
\hline & 79.2 & 7.0 & 18.2†t十 & $5 \cdot 1$ & $\mathrm{HC}$ & $61 \cdot 4^{*}+t+$ & 7.5 & $60 \cdot 2^{*}+t$ & $10 \cdot 7$ & $62 \cdot 0^{* \star *}+十 \dagger$ & 5.7 \\
\hline \multirow{6}{*}{$\begin{array}{c}\text { GP: } \begin{array}{l}\text { a form } \\
\text { total } \\
\text { a form } \\
\text { total }\end{array} \\
\text { GS }\end{array}$} & $169 \cdot 0$ & $7 \cdot 3$ & 48.3††† & 2.6 & SD & $139 \cdot 7 \dagger \dagger$ & 9.7 & $142 \cdot 9+\dagger$ & 13.7 & $165 \cdot 3+† \dagger$ & 12.9 \\
\hline & 228.0 & 8.9 & $126 \cdot 6+t+$ & 11.0 & & $153.2 t+t$ & $12 \cdot 6$ & $173.8+t+$ & 13.7 & $205.6+t+$ & 9.9 \\
\hline & 169.0 & $7 \cdot 3$ & $48 \cdot 3+t+$ & 2.6 & $\mathrm{HC}$ & $151 \cdot 0^{\star * \star}+\dagger$ & 9.7 & $160 \cdot 7^{* * \star} \dagger$ & $12 \cdot 1$ & $179 \cdot 8^{* \star \star}+\dagger$ & $15 \cdot 3$ \\
\hline & 228.8 & 8.9 & $126 \cdot 6 \dagger † \dagger$ & 11.0 & & $178.8^{* * *} \dagger \dagger \dagger$ & 12.5 & $184 \cdot 4^{* * *}+\dagger \dagger$ & $12 \cdot 3$ & $221.5^{\star *} \dagger$ & $12 \cdot 2$ \\
\hline & 0.50 & 0.02 & $0.50 \dagger \dagger$ & 0.03 & SD & $0.53 \dagger \dagger$ & 0.07 & $0.51 \dagger \dagger$ & 0.06 & $0.52 \dagger+\dagger$ & 0.07 \\
\hline & 0.50 & 0.02 & $0.50 t+$ & 0.03 & $\mathrm{HC}$ & $0.54^{*}+\dagger$ & 0.03 & $0.53^{* \star *}+$ & 0.06 & $0.52^{*}+\dagger$ & 0.03 \\
\hline
\end{tabular}

Mean values were significantly different from those for the SD group: ${ }^{\star} P<0.05,{ }^{* *} P<0.01,{ }^{* * *} P<0.001$.

Mean values were significantly different from the corresponding values before poisoning: $\uparrow P<0.05, \dagger \dagger P<0.01, \dagger \dagger \dagger P<0.001$.

$\ddagger$ For details of procedures, see pp. 473-474. 
(a)
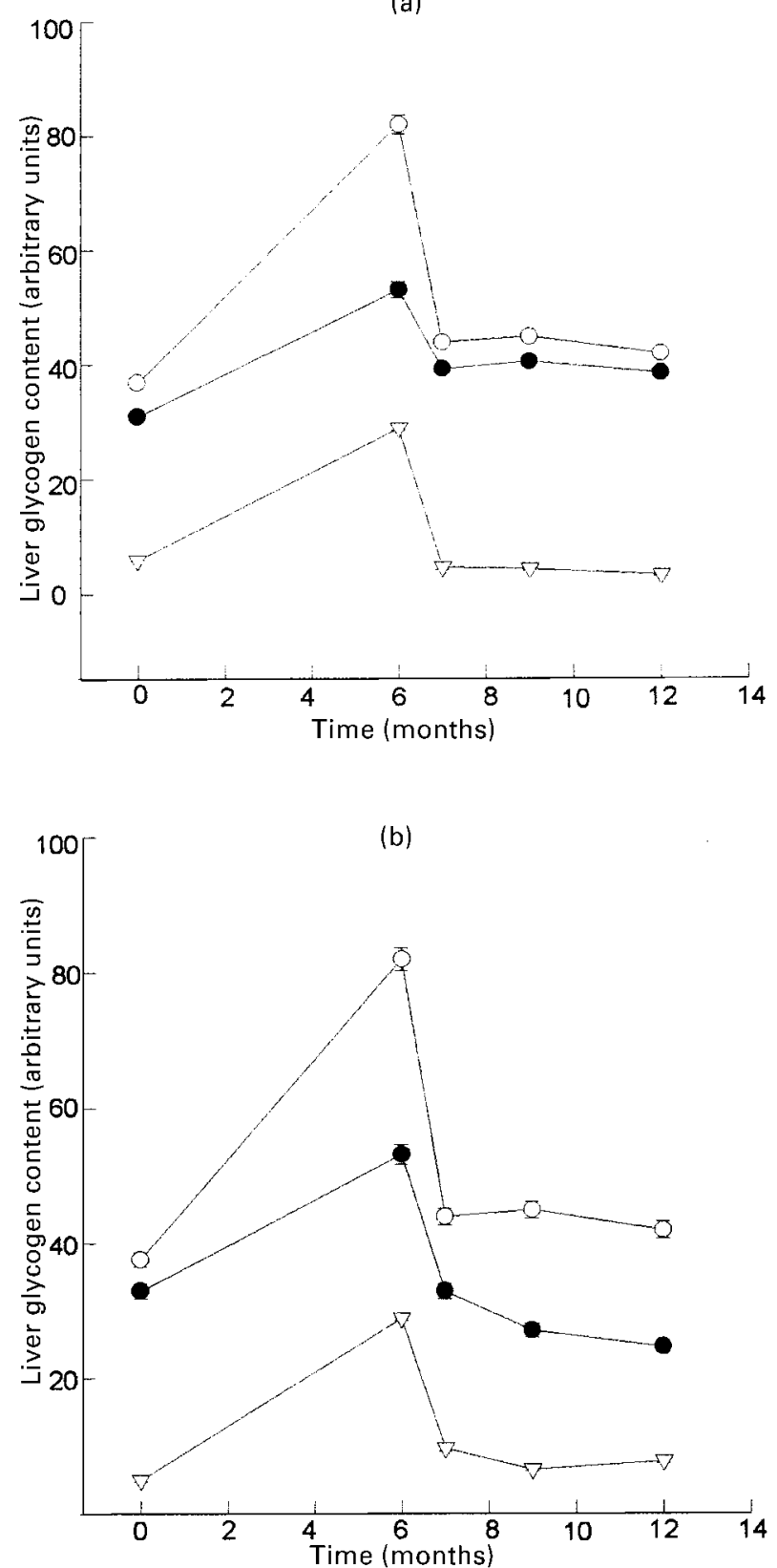

Fig. 4. Content of total glycogen $(\bigcirc)$, labile glycogen $(\bullet)$ and stable glycogen $(\nabla)$ in normal rats (time 0 ) and in rats undergoing induction of liver cirrhosis and subsequent rehabilitation on either (a) a highcarbohydrate diet or (b) a standard diet. Rats were subjected to chronic poisoning with carbon tetrachloride for 6 months and followed for a further 6 months after termination of poisoning. Values are means of five rats, with standard deviations indicated by vertical bars.

\section{Enzyme activities}

As seen from Table 2, activities of glycogen phosphorylase and glucose-6-phosphatase fell after the 6-month-long $\mathrm{CCl}_{4}$ poisoning, to 75 and $18 \%$ respectively of the normal levels of these enzymes and returned to normal somewhat faster in rats of the $\mathrm{HC}$ group.

\section{Discussion}

Liver cirrhosis, apart from producing essential changes in the hepatic structure, is also known to cause disturbances in various liver functions (Marchesini et al. 1984; Murata et al. 1985). Specifically, impairment of the glycogen and glucose metabolism in the cirrhotic liver has been shown to accompany the morphological alterations (Owen et al. 1981; Marchesini et al. 1982; Petrides \& de Fronzo, 1989).

Literature data on carbohydrate metabolism in the cirrhotic liver are not numerous and are rather controversial. Most authors report glucose intolerance and hyperinsulinaemia in liver cirrhosis (Pelkonen et al. 1981; Harewood et al. 1982; Keller et al. 1982; Riggio et al. 1982; Fernandez et al. 1983a,b). In addition, some studies suggest that production of glucose by the cirrhotic liver is impaired (Owen et al. 1981). At the same time, the blood glucose level in patients with chronic liver diseases is usually within normal levels or even somewhat higher (Kruszynska \& McIntyre, 1991; Kruszynska et al. 1993). This is partly explained by a substantial reserve capability of the liver for glucose production. As little as $20 \%$ of the entire functional mass of hepatocytes is believed to be necessary to maintain the glucose production by the liver in normal circumstances (Kruszynska \& McIntyre, 1991).

We have shown previously that the total glycogen content of hepatocytes in the cirrhotic liver increases three or four times compared with the norm (Kudryavtseva et al. 1992, 1994, 1996). There were also changes in the fractional composition of glycogen, especially with respect to the stable fraction, whereas the labile fraction changed mostly in resynthesis of the glycogen and glycogenolysis under different physiological conditions. The stable fraction changed markedly under pathological conditions and appeared to be an indicator of severe pathological alterations in the liver.

Information on activities of enzymes of carbohydrate metabolism in the cirrhotic liver is also rather scanty. Previously we have shown a decrease in activities of the key enzymes of carbohydrate metabolism, glycogen phosphorylase and glucose-6-phosphatase, in the cirrhotic liver, while the activity of glycogen synthase remained within normal limits (Kudryavtseva et al. 1992, 1994, 1996). Determination of glycogen synthase in the present study revealed an astonishing stability of activity throughout the experiment (Table 2), in spite of tremendous structural and functional changes that occurred in the cirrhotic liver.

In the course of post-poisoning rehabilitation, the activity of glycogen phosphorylase in rats of the SD and HC groups gradually reached the level characteristic of that in the normal liver (Table 2). It is to be noted that the activities of both total glycogen phosphorylase and its active form (glycogen phosphorylase $a$ ) returned to normal somewhat faster in rats of the $\mathrm{HC}$ group. At the same time, the proportion of phosphorylase $a$ throughout the rehabilitation remained higher than in the normal liver in animals of both the SD and HC groups.

Unlike glycogen phosphorylase, the activity of hepatic glucose-6-phosphatase in rats of both groups, although it rose severalfold as compared with the initial cirrhotic level, still did not reach the normal level even as long as 6 months 
after the end of the $\mathrm{CCl}_{4}$ poisoning (Table 2). The glucose6-phosphatase activity in both groups increased by approximately 3.5 times as early as 1 month after the termination of poisoning (Table 2). Subsequently, activity of this enzyme in the HC group remained at the same level, whereas in rats of the SD group it fell again within 6 months down to the level that was about half the normal level (Table 2).

Thus, after a period of hepatotoxicity, the use of a food with a high carbohydrate content promotes a somewhat faster and more complete recovery of the structure and functions of the liver.

\section{References}

Anthonius RJ, Endert E \& Sauerweinm HP (1991) Glucose and fat metabolism during short term starvation in cirrhosis. Gastroenterology 100, 731-737.

Barber A, Orrell S \& Bueding E (1967) Association of enzyme with rat liver glycogen isolated by rate-zonal centrifugation. Journal of Biological Chemistry 242, 4040-4044.

Diaz-Gomez MJ, de Castro CK, de Ferreyra EC, D'Acosta N, de Fenos OM \& Castro JA (1975) Mechanistic studies on carbon tetrachloride hepatotoxicity in fasted and fed rats. Toxicology and Applied Pharmacology 32, 101-108.

Fernandez S, Garcia G, Reimers G, Hernandez J, Lopez B, Nieto L \& Gomez B (1983a) Alteraciones del metabolismo de los hidratos de carbono en la hepatica. Leveles de insulinemia (Changes in carbohydrate metabolism in the cirrhotic liver. The levels of insulinaemia). Revista Espanola de las Enfermendades del Aparato Digestivo 63, 163-171.

Fernandez S, Garcia G, Reimers G, Hernandez J, Lopez B, Nieto L \& Gomez B (1983b) Alterationes del metabolismo de los hidratos de carbono en la cirrhosis hepatica. Hyperinsulinemia, hipersecretion o degradation deficiente? (Changes in carbohydrate metabolism in the cirrhotic liver. Hyperinsulinaemia, hypersecretion and hypodegradation?) Revista Espanola de las Enfermendades del Aparato Digestivo 63, 250-255.

Frederiks WM, Fronik GM, Marx F \& James J (1985) Influence of nutritional state on ischemic damage in rat liver. Liver 5, 342347.

Harewood MS, Proietto J, Dudley F \& Afford FO (1982) Insulin action and cirrhosis: insulin binding and lipogenesis in isolated adipocytes. Metabolism 31, 1241-1246.

Hers HG (1964) Glycogen storage disease. Advances in Metabolic Disorders. N.Y. 1, 1-44.

Hinson JF, Mays JB \& Cameron AM (1983) Acetaminopheninduced hepatic glycogen depletion and hyperglycemia in mice. Biochemical Pharmacology 32, 1979-1988.

Jennische E (1983) Possible influence of ischemia on the hepatic membrane potential in the rat. Differences between fed and fasted rats. Acta Physiologica Scandinavica 118, 69-73.

Kabadi UM, Sisenstein AB \& Konda J (1985) Elevated plasma ammonia level in hepatic cirrhosis: role of glucagon. Gastroenterology 88, 756-760.

Keller U, Sonnenberg GE, Burckhardt D \& Perruchoud A (1982) Evidence for an augmented glucagon dependence of hepatic glucose production in cirrhosis of the liver. Journal of Clinical Endocrinology and Metabolism 54, 961-968.

Kruszynska YG \& McIntyre N (1991) Relationship between insulin sensitivity, insulin secretion and glucose tolerance in cirrhosis. Hepatology 14, 103-111.

Kruszynska YG, Meyer-Albert A, Wollen N \& McIntyre N (1993) Energy expenditure and substrate metabolism after oral fructose in patients with cirrhosis. Journal of Hepatology $\mathbf{1 9}$, $241-451$
Kudryavtseva MV, Emelyanov AV, Sakuta GA \& Kudryavtsev BN (1996) Glycogen-forming function of hepatocytes under conditions of regeneration of the rat cirrhotic liver after a partial hepatectomy. Tsitologiya 38, 934-948.

Kudryavtseva MV, Emelyanov AV, Sakuta GA, Skorina AD, Sleptsova LA \& Kudryavtsev BN (1992) Cytofluorimetric study of the content of glycogen and its fractions in hepatocytes of patients with liver cirrhosis of different etiologies. Tsitologiya 34, 100-107.

Kudryavtseva MV, Kudryavtsev BN \& Rozanov YM (1972) Effect of duration of periodate oxidation on intensity and specificity of PAS reaction with standard Schiff reagent and with the reagent Schiff-Auramine $\mathrm{SO}_{2}$. Tsitologiya 14, 1357-1362.

Kudryavtseva MV, Kudryavtsev BN \& Rozanov YM (1974) Two glycogen fractions in rat liver cells (cytofluorimetric study). Tsitologiya 16, 851-858.

Kudryavtseva MV, Sakuta GA, Emelyanov AV, Sleptsova LA, Skorina AD \& Kudryavtsev BN (1994) Cytofluorimetric study of glycogen content and of activities of glycogen metabolism in human and animal hepatocytes in liver cirrhosis and under rehabilitation conditions. Tsitologiya 36, 200-210.

Kudryavtseva MV, Zavadskaya YE, Skorina AD, Smirnova SA \& Kudryavtsev BN (1983) Method of preparation of isolated human liver cells from material of vital punctate biopsies. Laborat. Delo 9, 21-22.

Lowry DH, Rosebrough NL, Farr A \& Randall RJ (1951) Protein measurement with the Folin phenol reagent. Journal of Biological Chemistry 193, 265-275.

Marchesini G, Bianchi GP, Cassarani S, Dondi C \& Zoli M (1984) Relationship of carbohydrate and amino acid metabolism in patients with liver cirrhosis. Advances in Hepatic Encephalopathy and Urea Cycle Diseases 21, 634-644.

Marchesini G, Zoli M, Dondi C, Angiolini A, Forlani G, Melli A, Bianchi FB \& Pisi E (1982) Blood glucose and glucoregulatory hormones in liver cirrhosis: a study of 24 hour profiles and of the role of portal-systemic shunting. Gastroenterology and Clinical Biology 6, 272-278.

Murata K, Ochiai Y \& Abashio K (1985) Polydispersity of acidic glycosaminoglycan components in human liver and the changes at different stages in liver cirrhosis. Gastroenterology 89, 12481257.

Nordlie R (1979) Multifunctional glucose-6-phosphatase: cell biology. Life Science 26, 2397-2404.

Owen O, Rechle F, Mazzoli M \& Kreulen J (1981) Hepatic gut and renal substrate flux rates in patients with hepatic cirrhosis. Journal of Clinical Investigation 68, 240-252.

Pelkonen R, Kallio H, Suoranta H \& Karonen S-L (1981) Plasma insulin, C-peptide and blood glucose in portal, hepatic and peripheral veins in liver cirrhosis. Effect of intravenous tolbutamide. Acta Endocrinologica 97, 496-502.

Petrides AS \& de Fronzo RA (1989) Glucose and insulin metabolism in cirrhosis. Journal of Hepatology 8, 107-114.

Proietto J, Alford FP \& Dudley FJ (1980) The mechanism of the carbohydrate intolerance of cirrhosis. Journal of Clinical Endocrinology and Metabolism 51, 1030-1036.

Pushpendran CK, Vasanti B, Shenoy B \& Eapen J (1977) Effect of carbon tetrachloride on glycogen metabolism in fasted and refed mice. Indian Journal of Experimental Biology 15, 992995.

Riggio O, Merli M, Cangiano C, Capocaccia R, Cascino A, Lala A, Leonetti F, Mauceri M, Pepe M, Rossi Fanelli F, Savioli M, Tamburrano G \& Capocaccia L (1982) Glucose intolerance in liver cirrhosis. Metabolism 31, 627-634.

Rosa F \& Johnson FB (1967) Enzyme digestion in the cytochemical demonstration of glycogen. Journal of Histology and Cytology 15, 14-21.

Rozanov YM \& Kudryavtsev BN (1967) Method of fluorescence 
cytophotometry for quantitative determination of DNA. Tsitologiya 9, 361-367.

Sarkisov DS (1987) Structural grounds of adaptation and compensation of disturbed functions. Meditsina Moscow 4, 1-56.

Solopaev BP (1985) Comparative study of regeneration of normal and pathologically altered organs. In Comparative Aspects of
Studies on Regeneration and Cellular Proliferation, pp. 279281 [BP Solopaev, editor]. Gorky, Russian Federation: Volgo Vyatskoe.

Swanson MA (1950) Phosphatases of liver glucose-6-phosphatase. Journal of Biological Chemistry 186, 647-659. 